\title{
Selection of approach and bypass for fetal-type posterior cerebral artery aneurysm: illustrative cases
}

\author{
Yoshichika Kikuta, MD, Koji Yamaguchi, MD, PhD, Tatsuya Ishikawa, MD, PhD, Takayuki Funatsu, MD, Yoshikazu Okada, MD, PhD, and \\ Takakazu Kawamata, MD, PhD
}

Department of Neurosurgery, Tokyo Women's Medical University, Tokyo, Japan

BACKGROUND Unlike in aneurysms of the adult-type posterior cerebral artery (PCA), in aneurysms of the fetal-type PCA, parent artery occlusion (PAO) results in vascular insufficiency and major ischemic strokes. Preservation or reconstruction of fetal-type PCAs is necessary to prevent these complications. Furthermore, it is necessary to select an appropriate bypass method and approach for revascularization of the PCA.

OBSERVATIONS The authors report 2 cases of aneurysms of fetal-type PCAs that were successfully treated with PAO with revascularization. A 38year-old man with a large unruptured right PCA aneurysm at the postcommunicating (P2) segment underwent trapping with superficial temporal artery-PCA bypass via the anterior temporal and subtemporal approaches. In addition, a 45-year-old woman with a left PCA aneurysm at the quadrigeminal (P3)-cortical (P4) segments resulting in subarachnoid hemorrhage underwent proximal clipping of the $\mathrm{P} 3$ segment via the occipital interhemispheric approach with an occipital artery-PCA bypass. Although she had perforator infarction, major ischemic stroke was prevented, and aneurysm occlusion was accomplished in both cases.

LESSONS Aneurysms of fetal-type PCAs pose a risk of ischemia due to PAO. The combined use of bypass and revascularization should be considered to prevent major ischemic stroke after occlusion of the fetal-type PCA. However, perforator infarction is a concern.

https://thejns.org/doi/abs/10.3171/CASE21240

KEYWORDS posterior cerebral artery aneurysm; fetal-type posterior cerebral artery; parent artery occlusion; bypass; approach

Posterior cerebral artery (PCA) aneurysms are infrequent lesions, accounting for approximately $0.7 \%-2.3 \%$ of all intracranial aneurysms. The treatment of PCA aneurysms is occasionally complicated because of the high frequency of fusiform aneurysms and proximity to important neuroanatomical structures. ${ }^{1}$ Trapping is widely considered a safe and effective strategy for fusiform and large to giant aneurysms of the adulttype PCA. However, clinical experience suggests that trapping of aneurysms of the fetal-type PCA leads to poor clinical outcomes owing to insufficient collateral circulation. ${ }^{2,3}$ Therefore, reconstruction of the parent artery is particularly important while repairing aneurysms of the fetal-type PCA. ${ }^{4,5}$ The approach to PCA aneurysms varies greatly depending on the site. Furthermore, bypass revascularization of the PCA is rarely performed, and there are few reports on its indications and therapeutic effects. $^{6-9}$ The pterional/anterior temporal approach (ATA) and subtemporal approach are selected for aneurysms in the precommunicating (P1)-postcommunicating (P2) and P2-quadrigeminal (P3) segments, and the posterior interhemispheric approach is selected for aneurysms in the P3-cortical (P4) segments. ${ }^{8-10} \mathrm{~A}$ combination of approaches provides sufficient space for revascularization procedures or clipping. ${ }^{9,11}$

We report 2 cases of aneurysms of the fetal-type PCA treated with bypass surgery. In addition, we reviewed the treatment strategies for microsurgical approaches, including revascularization of aneurysms of fetal-type PCAs.

ABBREVIATIONS 3D-CTA = three-dimensional computed tomography angiography; ATA = anterior temporal approach; DSA = digital subtraction angiography; $I C G$ = indocyanine green; $M R I=$ magnetic resonance imaging; $O A=$ occipital artery; $P 1$ segment = precommunicating segment; $P 2$ segment = postcommunicating segment; $\mathrm{P} 3$ segment $=$ quadrigeminal segment; $\mathrm{P} 4$ segment $=$ cortical segment; $\mathrm{PAO}=$ parent artery occlusion; $\mathrm{PCA}=$ posterior cerebral artery; $\mathrm{SCA}=$ superior cerebellar artery; STA = superficial temporal artery.

INCLUDE WHEN CITING Published June 21, 2021; DOI: 10.3171/CASE21240.

SUBMITTED April 16, 2021. ACCEPTED April 29, 2021.

(c) 2021 The authors, CC BY-NC-ND 4.0 (http://creativecommons.org/licenses/by-nc-nd/4.0/). 

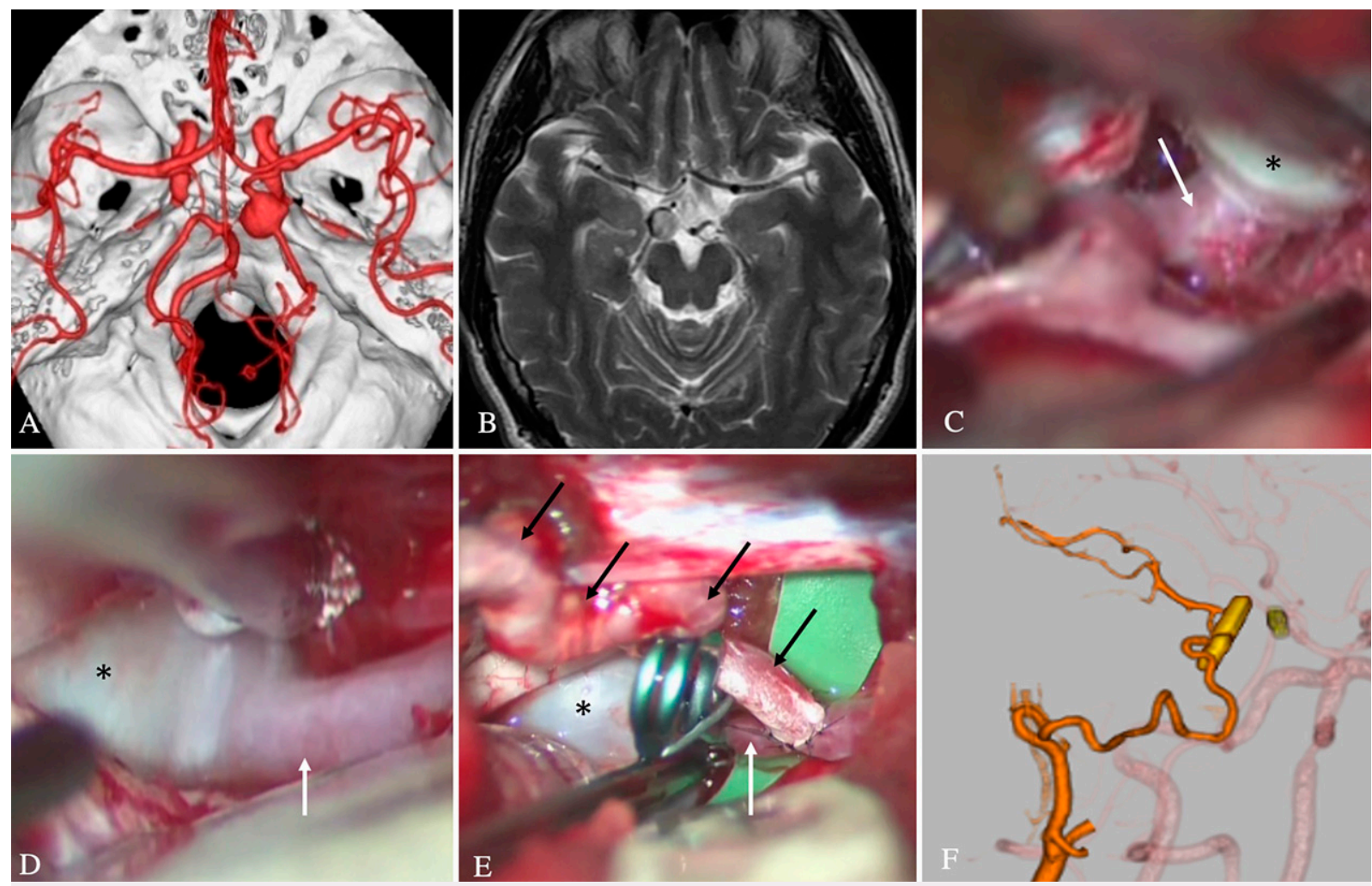

FIG. 1. Case 1. A: Preoperative 3D-CTA showing a large fusiform aneurysm in the right PCA (P1-P2 segments). B: T2-weighted MRI showing the aneurysm near the peduncle of the midbrain. C: PCA (arrow) proximal to the aneurysm (asterisk) identified via the ATA. D: The PCA (arrow) distal to the aneurysm (asterisk) identified via the subtemporal approach. E: Clipping of the PCA distal (white arrow) to the aneurysm (asterisk) after STA-PCA bypass (black arrows). F: Postoperative 3D-CTA shows disappearance of the aneurysm and good bypass patency.

\section{Illustrative Cases}

Two patients with aneurysms of fetal-type PCAs were treated with bypass surgery. The patient in case 1 underwent trapping with superficial temporal artery (STA)-PCA bypass for a large P2 aneurysm. The patient in case 2 underwent proximal occlusion with occipital artery (OA)-PCA bypass for a P3-P4 aneurysm. In these cases, preoperative balloon test occlusion was not performed because both falsepositive and false-negative test results have been reported previously. ${ }^{12,13}$ Informed consent was obtained from both patients.

\section{Case 1}

\section{Clinical Examination}

A 38-year-old man was incidentally diagnosed with a large unruptured right P2 aneurysm. Three-dimensional computed tomography angiography (3D-CTA) revealed an aneurysm that was approximately $1 \mathrm{~cm}$ superior to the posterior clinoid process and a fetal-type PCA (Fig. $1 \mathrm{~A}$ and $\mathrm{B}$ ). The aneurysm was fusiform, and we scheduled trapping of the aneurysm with a right STA-PCA (P2) bypass.

\section{Operation}

Both ends of the aneurysm and the anastomotic site could not be adequately exposed using a single surgical approach. Therefore, two approaches (the ATA and subtemporal approach) were used. First, the frontal and parietal branches of the STA were prepared. Next, frontotemporal craniotomy was performed, the sylvian fissure was dissected, and the right P1-P2 junction of the PCA and proximal side of the aneurysm were identified using the ATA (Fig. 1C). The distal side of the aneurysm could be exposed, but there was insufficient space for bypass. Therefore, STA-PCA ( $P 2)$ bypass and distal ligation were performed via the subtemporal approach (Fig. 1D and E). After STA-PCA (P2) bypass, patency was confirmed using indocyanine green (ICG) imaging, and proximal ligation was performed via the ATA. Sensory evoked potentials, motor evoked potentials, and visual evoked potentials were stable during surgery.

\section{Postoperative Course}

Postoperative 3D-CTA showed good patency of the bypass and no residual aneurysm (Fig. 1F). Magnetic resonance imaging (MRI) revealed no cerebral infarctions. The patient was discharged to home without any neurological deficits.

\section{Case 2}

\section{Clinical Examination}

A 45-year-old woman was diagnosed with a left P3-P4 aneurysm leading to subarachnoid hemorrhage, which was suspected to have occurred approximately 1 month earlier (Fig. 2A). Digital subtraction angiography (DSA) revealed a partially thrombosed aneurysm and fetal-type PCA. DSA further revealed that the parietooccipital and calcarine arteries originated from the aneurysm dome (Fig. 2B). We scheduled trapping of the aneurysm with a left OA-PCA (P4) bypass. 

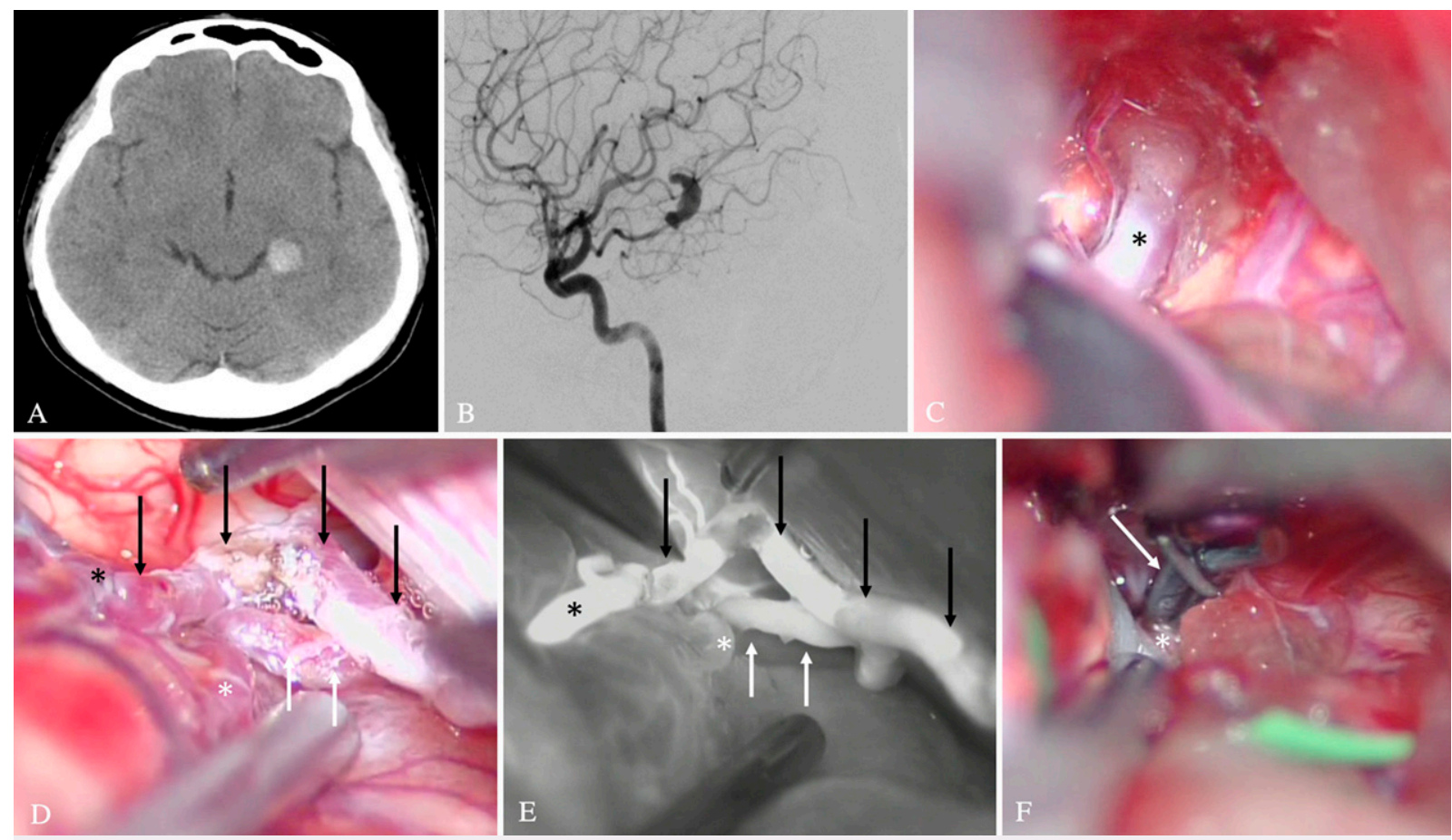

FIG. 2. Preoperative and intraoperative findings of case 2. A: Computed tomography showing a thrombosed aneurysm and unclear subarachnoid hemorrhage on the left side. B: Left internal carotid angiogram showing a large thrombosed aneurysm in the P3-P4 segments of the PCA. C: The P3 segment of the PCA (asterisk) proximal to the aneurysm identified via the occipital interhemispheric approach. D: The branches of the OA (black and white arrows) anastomosed to the calcarine artery (white asterisk) and the parietooccipital artery (black asterisk). E: ICG angiography showing good patency of bypass (white and black arrows). The white asterisk shows the calcarine artery, and the black asterisk shows the parietooccipital artery. F: Clip (arrow) applied to the proximal side of the aneurysm (asterisk).

\section{Operation}

The aneurysm and site of anastomosis were exposed using an occipital interhemispheric approach. First, the main trunk and branches of the OA were prepared. Next, a left occipital craniotomy was performed, the occipital interhemispheric fissure was dissected, and the PCA proximal to the aneurysm was exposed (Fig. 2C). The sites of anastomoses of the parietooccipital and calcarine arteries were identified, and the main trunk of the $\mathrm{OA}$ was anastomosed to the calcarine artery. After OA-PCA (calcarine artery) bypass, patency was confirmed using ICG imaging. Thereafter, another branch of the OA was anastomosed to the parietooccipital artery, and patency was again confirmed using ICG (Fig. 2D and E). Since the dome of the aneurysm was not filled during ICG imaging, only the easily exposed calcarine artery was ligated just distal to the aneurysm (Fig. 2F). Sensory evoked potentials, motor evoked potentials, and visual evoked potentials were stable during surgery.

\section{Postoperative Course}

Postoperative DSA showed good patency of the bypass and no residual aneurysm. MRI showed a small perforator infarction in the left thalamus (Fig. 3) but no deterioration in the postoperative modified Rankin Scale scores.
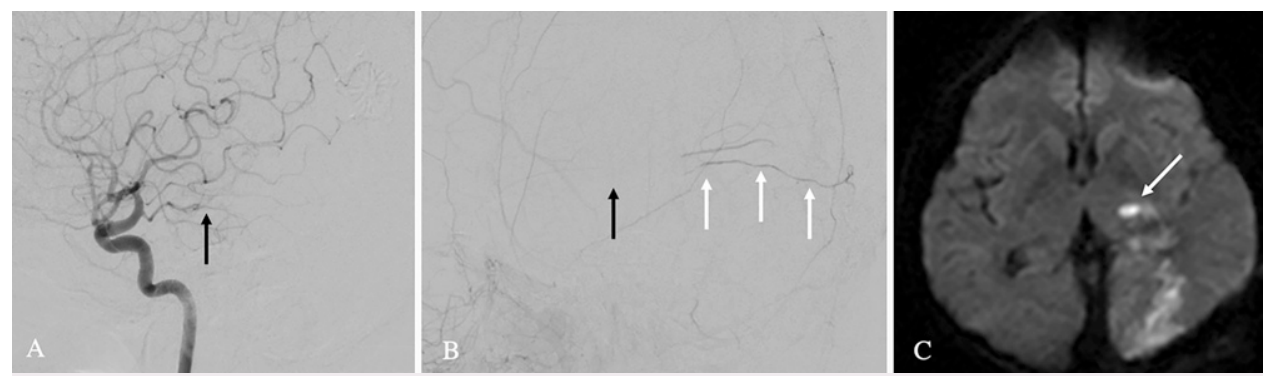

FIG. 3. Postoperative examination of case 2. A: Postoperative left internal carotid angiogram showing absence of aneurysm at the clipped portion (arrow). High signal intensity in the occipital lobe is caused by retraction. B: Postoperative left external carotid angiogram showing the PCA (white arrows) visualized from the bypass to the posterior side of the clipped portion (black arrow). C: Postoperative diffusion-weighted imaging showing perforator infarction involving the left thalamus (arrow). High signal intensity in the occipital lobe is caused by retraction. 


\section{Discussion}

Review of Treatment for Fetal-Type PCA Aneurysm

Parent artery occlusion (PAO) is an effective treatment for fusiform aneurysms in the PCA. However, PAO for aneurysms of the fetal-type
PCA is associated with a risk of infarction. Eighteen patients who underwent treatment for aneurysms of fetal-type PCAs have been reported previously. Of these 18 patients, cerebral infarction occurred in 11 of the 15 patients who had undergone PAO without revasculari-

TABLE 1. Review of fetal-type PCA aneurysms treated with PAO

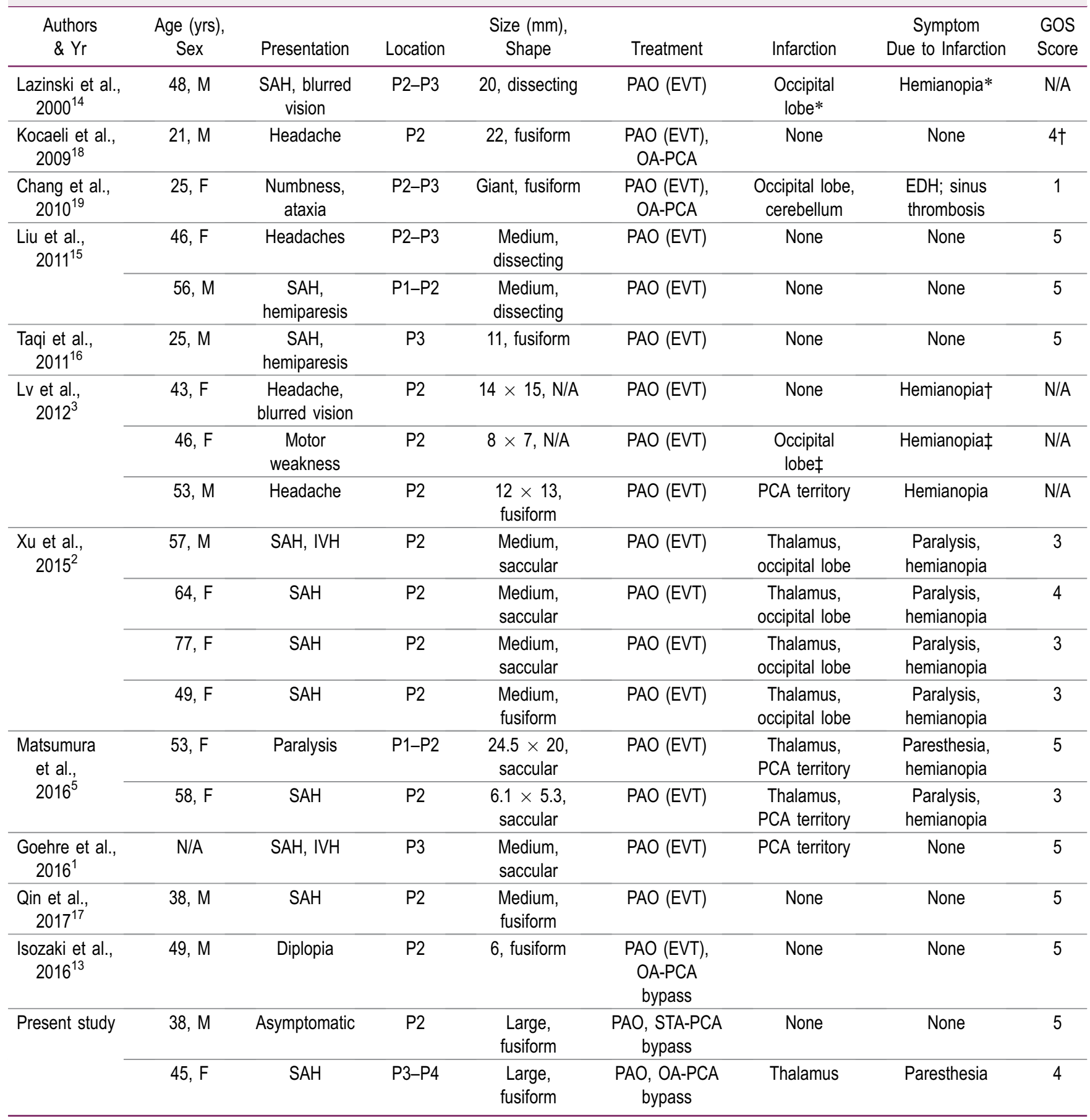

$\mathrm{EDH}=$ epidural hematoma; EVT = endovascular treatment; IVH = intraventricular hemorrhage; GOS = Glasgow Outcome Scale; N/A = not available; SAH = subarachnoid hemorrhage.

* Developed after PAO and persisted at 7 months.

$\dagger$ Baseline.

$\ddagger$ Insufficient leptomeningeal collateral circulation. 
zation, ${ }^{1-3,5,14-17}$ and symptoms were reported in 6 of the 11 cases (Table 1). The remaining 3 patients underwent internal trapping with OA-PCA bypass, which prevented cerebral infarction in 2 cases. ${ }^{13,18,19}$ Although in some patients with fetal-type PCA, PAO did not cause cerebral infarction, ${ }^{15-17}$ it is difficult to predict these ischemic complications, ${ }^{12,18,20}$ and recurrence or rupture of the aneurysm is more common without $\mathrm{PAO}^{3,16,17}$

\section{Observations}

Anatomical differences in the PCA have been shown to influence the cerebral collateral circulation. ${ }^{10,21,22}$ The proportion of fetal variants has been estimated to be $11 \%-46 \%$ on the basis of previous anatomical and angiographic studies. ${ }^{10,21}$ The malformation or absence of the P1 segment in fetal-type PCAs reduces collateral circulation, resulting in altered blood supply to the rostral territory of the thalamus. ${ }^{2,22}$ Anastomotic collateral channels are not easily recognizable on routine subtraction angiography and cannot be adequately evaluated prior to a planned artery occlusion. ${ }^{12}$ Therefore, it is difficult to determine whether PAO would be tolerated, especially in the case of an aneurysm of a fetal-type PCA.

The surgical approach for PCA aneurysms was selected on the basis of the morphology and location of the aneurysm (Fig. 4). From the point of view of bypass surgery, the ATA could obtain a working depth similar to that of the subtemporal approach. However, identifying the distal end of the aneurysm and obtaining sufficient space for bypass would have been difficult in case 1.23,24 The subtemporal approach can provide enough space for revascularization procedures. However, the high position of the PCA and the presence of the temporobasal bridging vein complicate this approach to the PCA by necessitating retraction of the temporal lobe with the possibility of causing contusion and neurological deficits. ${ }^{8,25}$ The posterior interhemispheric approach is appropriate for the distal segment of the PCA. ${ }^{26}$ This approach provides a relatively wide working space, and bypass surgery is easily performed. Furthermore, it avoids injury to the temporobasal bridging veins encountered during conventional
STA-superior cerebellar artery (SCA)/STA-PCA bypass through the subtemporal approach. ${ }^{27}$ However, this approach does not permit control of the proximal PCA.

Bypass surgery can prevent hemodynamic ischemia after sacrificing the fetal-type PCA ${ }^{28-30}$ However, infarction of the perforating artery territory caused by the blind end of the fetal-type PCA is an unsolved problem. ${ }^{6,9}$ Furthermore, high incidences of surgical complications of STA-SCA and STA-PCA bypass surgeries have been reported, with the most frequent complications being hematoma and/ or edema caused by temporal lobe retraction. ${ }^{19,29}$ Recently, combined surgical bypass and endovascular PAO procedures have been reported, which could prevent deep operative fields. However, antithrombotic therapy induces hemorrhagic complications. ${ }^{13,19,31}$ Of note, suitable approaches and techniques can prevent serious operative complications. For aneurysms of fetal-type PCAs, bypass surgery should be considered to prevent ischemic complications, regardless of the results of balloon test occlusion. ${ }^{13}$

Treatment modalities that preserve the parent artery of fusiform aneurysms include stent-assisted coiling and flow diverters. Stentassisted coiling for the treatment of complex PCA aneurysms is safe and durable, with a relatively low rate of complications and a relatively high rate of complete occlusion at the long-term follow-up. ${ }^{32,33}$ However, cases of recurrence and postoperative rebleeding have been reported. ${ }^{3,17}$ Flow diverters have a high complete aneurysm occlusion rate. Both of the cases presented could have been treated with flow diverters. However, they are associated with higher complication rates, especially in PCA aneurysms. PCA aneurysms are frequently fusiform, large, and long. These induce clot formation and require the placement of multiple long flow diverters. More metal within the parent artery may result in an increased risk of thromboembolic events for the parent artery and the perforators. ${ }^{34,35}$ Furthermore, in the acute phase of ruptured aneurysms, a hypercoagulable status could be a risk factor for stent thrombosis. In addition, high-intensity antiplatelet therapy can increase the risk of hemorrhagic complications. ${ }^{36,37}$ Fusiform and ruptured cases are at risk for requiring flow diverter placement. Our first case was fusiform and our second case

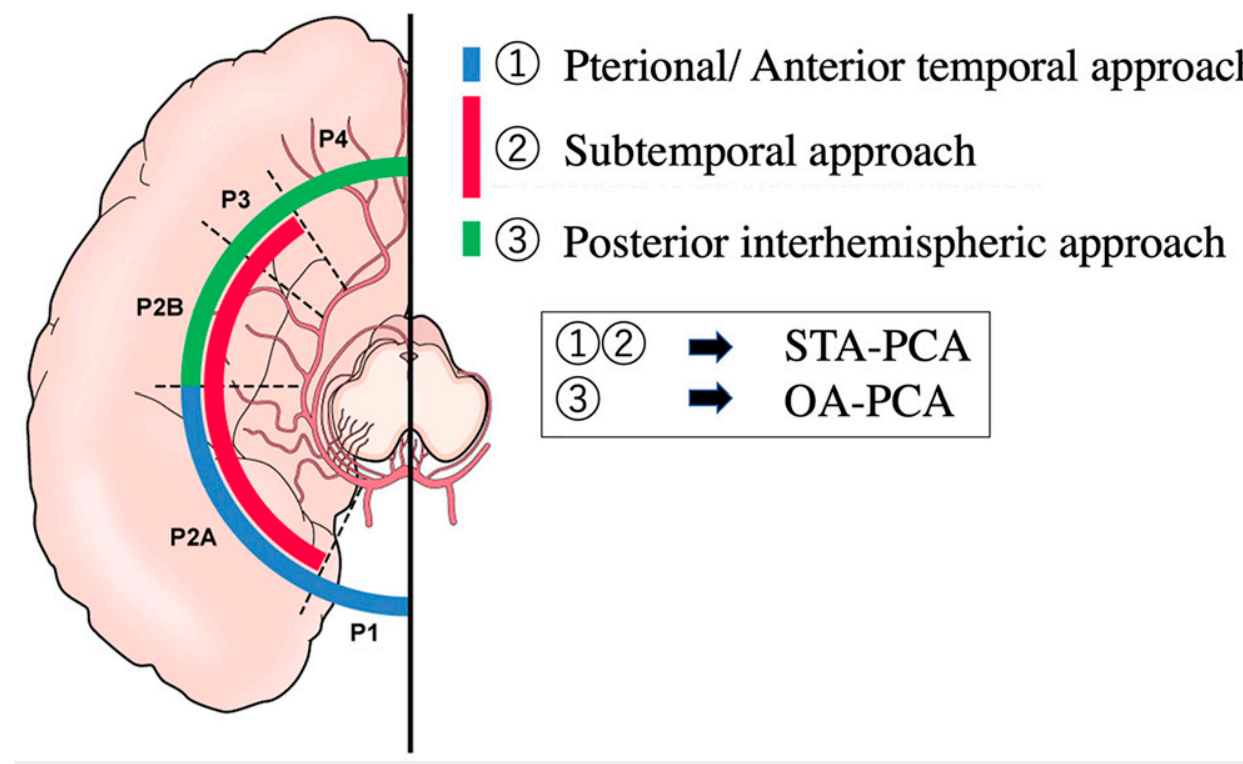

FIG. 4. Approach to each segment of the PCA and bypass options for each approach. P2A = anterior postcommunicating segment; $\mathrm{P} 2 \mathrm{~B}=$ posterior postcommunicating segment. 
was ruptured, both of which indicated the need for bypass and revascularization. This method is also a useful alternative for patients who may not be eligible for endovascular treatment, such as those who are unable to take antiplatelet drugs.

\section{Lessons}

There is a higher risk of ischemia after PAO in aneurysms of fetal-type PCAs than in aneurysms of adult-type PCAs. Therefore, concurrent bypass should be considered; however, the approach differs greatly depending on the site of the aneurysm. Ischemia can be prevented by choosing the appropriate approach and bypass, but the problem of perforator infarction remains unsolved.

\section{References}

1. Goehre F, Jahromi BR, Lehecka M, et al. Posterior cerebral artery aneurysms: treatment and outcome analysis in 121 patients. World Neurosurg. 2016;92:521-532.

2. $\mathrm{Xu} \mathrm{J}, \mathrm{Xu} \mathrm{L}, \mathrm{Wu} Z$, et al. Fetal-type posterior cerebral artery: the pitfall of parent artery occlusion for ruptured $\mathrm{P}_{2}$ segment and distal aneurysms. J Neurosurg. 2015;123(4):906-914.

3. Lv X, Li Y, Yang X, et al. Potential proneness of fetal-type posterior cerebral artery to vascular insufficiency in parent vessel occlusion of distal posterior cerebral artery aneurysms. J Neurosurg. 2012;117(2):284-287.

4. Sturiale CL, De Waure C, Della Pepa GM, et al. Endovascular treatment of the posterior cerebral artery aneurysms: single-center experience and a systematic review. World Neurosurg. 2016:91:154-162.

5. Matsumura $\mathrm{H}$, Kato $\mathrm{N}$, Fujiwara $\mathrm{Y}$, et al. Endovascular treatments for posterior cerebral artery aneurysms and vascular insufficiency of fetal-type circulation after parent artery occlusion. J Clin Neurosci. 2016:32:41-46.

6. Hara T, Arai S, Goto Y, et al. Bypass surgeries in the treatment of cerebral aneurysms. Acta Neurochir Suppl (Wien). 2016;123:57-64.

7. Kalani MY, Ramey W, Albuquerque FC, et al. Revascularization and aneurysm surgery: techniques, indications, and outcomes in the endovascular era. Neurosurgery. 2014;74(5):482-498.

8. Kawashima A, Andrade-Barazarte $H$, Jahromi BR, et al. Superficial temporal artery: distal posterior cerebral artery bypass through the subtemporal approach: technical note and pilot surgical cases. Oper Neurosurg (Hagerstown). 2017;13(3):309-316.

9. Ota N, Goehre F, Miyazaki T, et al. Bypass revascularization applied to the posterior cerebral artery. World Neurosurg. 2016;96:460-472.

10. Fernandez-Miranda JC, de Oliveira E, Rubino PA, et al. Microvascular anatomy of the medial temporal region: part 1: its application to arteriovenous malformation surgery. Neurosurgery. 2010;67(suppl operative 3):ons237-ons276.

11. Campero A, Tróccoli G, Martins C, et al. Microsurgical approaches to the medial temporal region: an anatomical study. Neurosurgery. 2006;59(4 suppl 2):ONS279-ONS308.

12. Ciceri EF, Klucznik RP, Grossman RG, et al. Aneurysms of the posterior cerebral artery: classification and endovascular treatment. AJNR Am J Neuroradiol. 2001;22(1):27-34.

13. Isozaki M, Arai $H$, Neishi $H$, et al. Super-selective balloon test occlusion of the posterior communicating artery in the treatment of a posterior cerebral artery fusiform aneurysm: a case report. NMC Case Rep J. 2016;3(4):129-131.

14. Lazinski D, Willinsky RA, TerBrugge K, Montanera W. Dissecting aneurysms of the posterior cerebral artery: angioarchitecture and a review of the literature. Neuroradiology. 2000;42(2):128-133.

15. Liu L, He H, Jiang C, et al. Deliberate parent artery occlusion for non-saccular posterior cerebral artery aneurysms. Interv Neuroradiol. 2011;17(2):159-168.
16. Taqi MA, Lazzaro MA, Pandya DJ, et al. Dissecting aneurysms of posterior cerebral artery: clinical presentation, angiographic findings, treatment, and outcome. Front Neurol. 2011;2:38.

17. Qin X, Xu F, Maimaiti $Y$, et al. Endovascular treatment of posterior cerebral artery aneurysms: a single center's experience of 55 cases. J Neurosurg. 2017;126(4):1094-1105.

18. Kocaeli H, Chaalala C, Abruzzo TA, Zuccarello M. Results of surgical management for posterior cerebral artery aneurysms: 7-year experience in the endovascular era. Acta Neurochir (Wien). 2009;151(12):1583-1591.

19. Chang SW, Abla AA, Kakarla UK, et al. Treatment of distal posterior cerebral artery aneurysms: a critical appraisal of the occipital artery-to-posterior cerebral artery bypass. Neurosurgery. 2010;67(1):16-26.

20. Kashiwazaki D, Ushikoshi S, Asano T, et al. Endovascular treatment for aneurysms of the posterior cerebral artery: 12 years experience with 21 cases. Acta Neurochir (Wien). 2011;153(11): 2151-2158.

21. Lambert SL, Williams FJ, Oganisyan ZZ, et al. Fetal-type variants of the posterior cerebral artery and concurrent infarction in the major arterial territories of the cerebral hemisphere. J Investig Med High Impact Case Rep. 2016;4(3):2324709616665409.

22. van Raamt $A F$, Mali WP, van Laar PJ, van der Graaf $Y$. The fetal variant of the circle of Willis and its influence on the cerebral collateral circulation. Cerebrovasc Dis. 2006;22(4):217-224.

23. de Oliveira JG, Párraga RG, Chaddad-Neto F, et al. Supracerebellar transtentorial approach-resection of the tentorium instead of an opening - to provide broad exposure of the mediobasal temporal lobe: anatomical aspects and surgical applications. Clinical article. J Neurosurg. 2012;116(4):764-772.

24. Mascitelli JR, Gandhi S, Tayebi Meybodi A, Lawton MT. The oculomotor-tentorial triangle. Part 2: a microsurgical workspace for vascular lesions in the crural and ambient cisterns. J Neurosurg. 2019;130(5):1435-1445.

25. Hori T, Tabuchi S, Kurosaki M, et al. Subtemporal amygdalohippocampectomy for treating medically intractable temporal lobe epilepsy. Neurosurgery. 1993;33(1):50-57.

26. Chi JH, Lawton MT. Posterior interhemispheric approach: surgical technique, application to vascular lesions, and benefits of gravity retraction. Neurosurgery. 2006;59(1 suppl 1):ONS41-ONS49.

27. Kazumata K, Yokoyama Y, Sugiyama T, Asaoka K. Occipitalposterior cerebral artery bypass via the occipital interhemispheric approach. Surg Neurol Int. 2013;4:90.

28. Iwama T, Hashimoto N, Hayashida K. Cerebral hemodynamic parameters for patients with neurological improvements after extracranial-intracranial arterial bypass surgery: evaluation using positron emission tomography. Neurosurgery. 2001;48(3):504-512.

29. Ogawa A, Kameyama M, Muraishi K, et al. Cerebral blood flow and metabolism following superficial temporal artery to superior cerebellar artery bypass for vertebrobasilar occlusive disease. J Neurosurg. 1992;76(6):955-960.

30. Low SW, Teo K, Lwin S, et al. Improvement in cerebral hemodynamic parameters and outcomes after superficial temporal arterymiddle cerebral artery bypass in patients with severe stenoocclusive disease of the intracranial internal carotid or middle cerebral arteries. J Neurosurg. 2015;123(3):662-669.

31. Sato K, Endo H, Fujimura M, et al. Endovascular treatments in combination with extracranial-intracranial bypass for complex intracranial aneurysms. World Neurosurg. 2018;113:e747-e760.

32. Xue G, Tang H, Liu P, et al. Safety and long-term efficacy of stentassisted coiling for the treatment of complex posterior cerebral artery aneurysms. Clin Neuroradiol. 2021;31(1):89-97.

33. Huang Q, Liu J, Zhao R, et al. The safety and efficacy of stenting in the treatment of complex posterior cerebral artery aneurysms: a 
seven-case report and literature review. Clin Neuroradiol. 2013; 23(3):175-187.

34. Wallace AN, Grossberg JA, Almandoz JED, et al. Endovascular treatment of posterior cerebral artery aneurysms with flow diversion: case series and systematic review. Neurosurgery. 2018;83(4): 790-799.

35. Griessenauer CJ, Ogilvy CS, Adeeb N, et al. Pipeline embolization of posterior circulation aneurysms: a multicenter study of 131 aneurysms. J Neurosurg. 2019:130(3):923-935.

36. Bechan RS, Sprengers ME, Majoie CB, et al. Stent-assisted coil embolization of intracranial aneurysms: complications in acutely ruptured versus unruptured aneurysms. AJNR Am J Neuroradiol. 2016;37(3):502-507.

37. Ryu CW, Park S, Shin HS, Koh JS. Complications in stent-assisted endovascular therapy of ruptured intracranial aneurysms and relevance to antiplatelet administration: a systematic review. AJNR Am J Neuroradiol. 2015;36(9):1682-1688.

\section{Disclosures}

The authors report no conflict of interest concerning the materials or methods used in this study or the findings specified in this paper.

\section{Author Contributions}

Conception and design: Ishikawa, Kikuta, Funatsu, Okada, Kawamata. Acquisition of data: Ishikawa, Kikuta, Okada. Analysis and interpretation of data: Ishikawa, Kikuta, Okada. Drafting the article: Ishikawa, Kikuta, Funatsu, Okada. Critically revising the article: Ishikawa, Kikuta, Okada. Reviewed submitted version of manuscript: Ishikawa, Kikuta, Okada. Approved the final version of the manuscript on behalf of all authors: Ishikawa. Administrative/technical/material support: Ishikawa, Okada. Study supervision: Ishikawa, Yamaguchi, Okada, Kawamata.

\section{Correspondence}

Tatsuya Ishikawa: Tokyo Women's Medical University, Tokyo, Japan. tishikawa@twmu.ac.jp. 